\title{
Admission of and Service Provision for Deaf Students at a University of Technology
}

\author{
Professor Kholeka Connie Moloi \\ Vaal University of Technology, Faculty of Human Sciences, Vanderbijpark,1900 South Africa \\ Email: conniem@vut.ac.za
}

Miss Reitumetse Rejoyce Motaung
Vaal University of Technology, Faculty of Human Sciences, Vanderbij/park,1900 South Africa
Email: Reitumetsem8@gmail.com

Doi:10.5901/mjss.2014.v5n10p370

\begin{abstract}
Research reveals that there is a lack of research on Deaf students in tertiary institutions in South Africa and that there are not many tertiary institutions which enrol Deaf students and provide them with sign language interpreters. While a considerable amount of research has been done on what constitutes Deaf students' barriers to gaining access to institutions of higher learning, not as much is known about the potential solutions to these problems. In addition, there is a lack of inquiry into the value of support services such as interpreting, note taking, real-time captioning and tutoring, particularly with regard to their impact on academic achievement. The purpose of this paper is to explore ways in which the quality of education for deaf students can be enhanced through access and support services in one institution of higher education.
\end{abstract}

Keywords: access, service, deaf, South African Sign Language, Higher Education Institution, human rights,

\section{Introduction and Background}

Deaf children's access to and ability to receive education and information is one of the oldest discussions in the history of Deaf people. Although the Education White Paper 6 of 2001 underscores the importance of mainstream education in South Africa, not all higher institutions adhere to it. There is a lack of research on Deaf students in tertiary institutions in South Africa and many institutions of higher learning, such as the University of Technology under study, do not enrol Deaf students. To accommodate a diversity of learning needs, it is critical to address learning and access barriers because education institutions are required by the government to provide education support services to learners (Department of Education, 1997). According to a 2012 report by the World Association of Sign Language Interpreters (WASLI), one in ten babies in South Africa is born with some degree of hearing loss and it is estimated that the number of deaf people is about 600000 (including people who are Deaf/hard of hearing and deafened). To ensure the education of deaf children, there are 64 schools for the deaf in South Africa but only 12 of them offer schooling up to grade 12. These schools are located in three provinces. Although South African Sign language (SASL) is not recognised as an official language in the country, the South African Act of 1996 states that SASL is to be a medium of instruction in schools for the Deaf; furthermore, the constitution clearly states that the on-going development and use of SASL must be promoted. In reality, however, as detailed by Aarons and Akach (2002: 129), the existing state of schools for the Deaf does not conform to the stipulations of the South African schools Act. Deaf learners are not educated through the medium of a signed language because there are very few teachers of the Deaf who are fluent in a signed language. It is reported in the WASLI document that only $14 \%$ of teachers in South African schools for the Deaf can sign fluently; even more disturbing is the fact that SASL is still not a school subject.

Given the state of affairs mentioned above, one could assume that the problem is the lack of professional service in this field. Until a few years ago there was no accurate training for interpreters although it is now offered in some universities in the country. A challenge facing interpreters, however, is that South Africa does not have an interpreters' association, a situation which is now being remedied by establishing a group called 'Mzansi Ditoloki' (South African Interpreters). This is a general group which people join on Facebook, BBM and other media to share information about SASL interpreting. According to statistics supplied by the Deaf Association of South Africa (DeafSA), there are 100 registered interpreters on the DeafSA database and only half of them are trained.

A report by the National Commission on Special Needs in Education and Training (NCSNET)/National Committee for Education Support Services (NCESS) states that children with special needs can be provided for in an inclusion model, by designing the inclusion in such a way that the child's education barriers are removed. A significant way in 
which Deaf children differ from children with other special needs is that they use a different language, namely sign language (Ganiso, 2012: 42). One of the key factors of an inclusive learning environment is the provision of support services or 'access services' (Lang, 2002: 270). Access or support services refer to South African Sign Language (SASL) interpreters, tape recorders and academic support services to Deaf and hard-of-hearing students. Magongwa (2008: 3738) adds that since Deaf and hard-of-hearing students participate in the teaching and learning process through a visual language, a speaking and hearing environment is inaccessible to them without support or access services. Other common types of educational support services needed by Deaf students generally are academic advice, interpretation, tutoring, note-taking and real-time captioning. The latter is an information technology where the speaker's message is translated into an electronic text as she/he speaks. The accommodation of Deaf students in higher education is a complex phenomenon and the researcher believes that in order to service these students there should be a structured unit that is tasked to support disabled students. The purpose of this paper, therefore, is to explore ways in which institutions of higher learning can work towards achieving a mainstream higher education where all students, regardless of their incapacities, can gain access and support services.

\section{Problem Statement}

The Constitution (Act 108 of 1996, Section 1a) founded by the South African democratic government states that the rights and benefits of citizenship are based on the values of human dignity, the achievement of equality and the advancement of human rights. These values call on all of us to take up the responsibility and challenge of building a civilised and caring society, not for the few, but for all South Africans. Subsequent to that, the South African Government started to address some of the inequalities in education with the issuing of the White Paper 3 in 1997, which introduced the transformation of the education system allowing students to attend schools of their choice and having only one system of education for all students, regardless of their race, religion or culture (Department of Education, 1997).

Yet many institutions have a disability policy only as a legal obligation, but do not apply what needs to be done (Matshedisho 2007: 686). Like the institution under study, their policy speaks of their commitment to equal opportunities for staff and students with disabilities; it also states that there will be equal access to education and employment of people with disabilities. However, it is with disappointment that we report that there are no Deaf students enrolled at this institution. Mazoue (2011 4) also argues that, despite the South African Constitution (1996) providing a Bill of Rights which states that no person may be discriminated against on any grounds, including disability, life for Deaf people in South Africa is still very difficult. The majority of Deaf children still go to special schools for the Deaf, because the mainstream schools do not have facilities such as sign language interpreters to teach them and this is also true in the case of higher institutions. These special schools, however, generally have a lower level of education than the mainstream schools, especially with regard to English and as documented in the World Association of Sign Language Interpreters (WASLI) report of 2012, the average Deaf school-leaver has a reading age of eight, meaning that these Deaf people are effectively excluded from higher education.

The authors hold that if South African Deaf learners were taught through the medium of a signed language there would be no barrier to learning. The spoken language is a barrier to the Deaf child. Ganiso (2012: 43) is of the view that hearing learners can acquire a new spoken language through exposure, but Deaf learners cannot. Once Deaf learners are given fair and equal access to learning contexts, through the use of signed language as a medium of instruction and the language of communication in the broader learning context, they will no longer experience a barrier to learning and development. The researcher believes that Deaf people have a very strong sense of their own culture, and that their communication problems in the hearing world come as a result of the absence of sign language interpreters for them. Deaf people are certainly not a liability as they can communicate with each other very well and enjoy socialising together. Therefore, their challenge is similar to any language barrier faced by a hearing person who either does not understand another spoken language or is not fluent in it.

Once more, as recorded by a national survey on the status of disability support in higher education, the academic support services provided for students with disabilities in most institutions by the Department of Education, through its Council on Higher Education, are limited to blind and physically disabled students, with little provision being made for Deaf students. Matshedisho (2007: 697) contends that provision of support for disabled students in South Africa finds itself in the contradictory position of supporting disability rights and the social model of disability while being embedded in the practice and legacy of benevolence. This position is evident from the challenges that disability support services face and the lack of political commitment to disability issues by government and higher education management structures. It is for this reason that the author maintains that the present status of equal access for disabled students in higher education is based on policies that are not implemented. 


\section{Objectives of the Study}

\subsection{The primary objective}

The main aim of this study is to investigate access and service support for Deaf students in higher institutions.

\subsection{Theoretical objectives}

To achieve the main objective, the following theoretical objectives are set:

- To provide an overview of different types of support services needed in higher education in training learners with disabilities.

- To determine from the literature the barriers to deaf students' access to higher institution.

- To conduct a literature review on how the use of sign language can improve literacy for Deaf students.

\section{Literature Review}

Donald, Lazarus \& Lolwana (1997: 172) found that academic support services such as tutoring existed for people with disabilities in the former apartheid regime in South Africa but with minimal effect. Since schools for students with disabilities and the Deaf were separated by the racial politics of the education system, there were inequalities in the provision of support services. Support services such as speech therapy provided by some schools were ineffective. As Donald et al. explain, the reason for the inefficiency is that the South African education system has a long history of gross inequalities and inconsistencies between the various social services, racial segregation and between rural and urban contexts. Furthermore, professional consistency between the components of educational support services failed because Deaf people's opportunities for entry into higher education increased after the adoption of a democratic constitution in 1996. These opportunities are made possible by the provision of education support services like SASL interpreters for Deaf students in order to overcome their unique barriers to learning. Education support services are the 'key to equal participation in the learning process' (Department of Education, 1997: 12). Hence their availability to Deaf students in the context of equal participation in the learning process is worth exploring (Magongwa 2008: 15).

\subsection{Understanding deafness}

Dating as far back in 1993 Dolnick (1993: 37) was already advocating the view that the Deaf community are anything but handicapped; they are simply a linguistic minority speaking a visual language and are not in need of a cure. From the literature the author learned that, like members of other ethnic groups, Deaf people come with a wide range of identities. It is common practice to use a capital D when identifying someone as culturally Deaf and a member of the Deaf community. Deaf people who have difficulties with vision may identify as Deafblind and some use a lower-case $d$ for deaf, which speaks to the medical model and focuses on audiological status. (Whyte, Aubrecht, McCullough, Lewis \& Thompson-Ochoa (2013) maintain that Deaf people are part of a cultural group, a linguistic minority, and that it is living in a non-signing world that is actually disabling, not the experience of being Deaf. Deaf people share a collective name, language, culture, history, values, customs and behavioural norms, feelings of community and relationship, arts and literature and social structures. Being Deaf is a biological characteristic just like being Black or White, female or male and is not a condition; it is a way of being. Reagan (2008: 170) also states that within a sociocultural construction of deafness, the fact of audiological deafness is neither a necessary

nor a sufficient condition for cultural deafness. Hearing children of Deaf people (technically referred to as 'CODAs', or 'Children of Deaf Adults') who grow up with a natural sign language as their first language are at least in some significant ways potential members of the Deaf culture, just as older hearing people who lose their hearing are, under normal circumstances, not Deaf but are merely people who can no longer hear.

\subsection{Support service aids to assist Deaf students in a tertiary environment}

Universities that already accommodate Deaf students have a division called the Disability Unit dedicated to providing support and guidance to students with disabilities, including the Deaf, for ease of adjustment to the university environment. This unit has enabled universities to lead the way in making university degrees attainable for students with disabilities and the Deaf, thus aligning themselves with the principles of the South African and international policy on 
inclusive education (Magongwa 2008: 21). The services they provide include the availability of South African Sign Language interpreters, note-takers, tutors, adaptive devices, invigilators, application for extra time for tests and examinations, computer training, intervention related to physical access to buildings and assistance with bursary and loan applications. In the case of Deaf students it is important to appoint an appropriate candidate to head the Disability Unit. In the literature the findings of other researchers reveal that the person involved in the management of services for Deaf and hard-of-hearing students' needs to have a detailed knowledge of Deaf people and their needs in a hearing environment as well as the ability to use SASL as this will eliminate the need for a third party to communicate with the students (Magongwa 2008: 22).

Support for Deaf students is a continuous process; it does not stop when interpreters are hired. For some students being granted access at a university comes with the stigma of being different and, in many institutions of higher learning, the need to expend valuable time and energy in arranging the appropriate logistics is an on-going responsibility. Lang (2002: 270) is of the view that despite the use of such services by many students in higher education in South Africa and internationally, there is little research published to guide those interested in providing such support. This could be the reason that many universities still do not provide service support for Deaf students.

\subsubsection{Interpreting}

Mazoue (2011: 84) is of the view that sign language interpreters play a key role in assisting Deaf students in overcoming some of the problems generated by their poor literacy levels. They not only translate what is said by the lecturer during lectures and act as the voice of Deaf students when they want to ask a question or need further explanation, but they make notes of the subject matter in a simplified form of English when necessary, such as when the language in the text book is too difficult for the Deaf students to understand. The limitations of their low literacy levels make it necessary for interpreters to have notes in a form which the Deaf students can understand, or which can be explained to the students by the interpreters; this is essential as some of the language used in lectures and textbooks is unfamiliar to the Deaf students. Without doubt the Deaf students would have to learn the correct vocabulary but the interpreters would have to clarify the meaning of the words.

Stewart and Kluwin (1996: 30) observe that when research on sign language linguistics began, signed languages were recognised as complete, unique languages of equal value to spoken languages. As a result, as articulated by Swift (2012: 45), the Deaf community began to develop an intense pride which resulted in a rejection of the paternalistic help they were often given and, consequently, the interpreter was seen as a neutral professional who 'just interpreted'. To avoid the latter and create harmonious environments, interpreting for Deaf students in an educational setting should be regarded as requiring a unique set of skills, allowing an individual to simplify communication in the auditory and visual channels. Therefore, as Lang (2002: 271) emphasised, interpreters need to be more aware of the barriers that Deaf students experience as identified in many studies. Such an awareness may enable them to adapt their interpreting and advise teachers and students accordingly.

\subsubsection{Note taking}

One of the main characteristics of learning for Deaf students in mainstream universities is the students' dependence on a third party to provide access to information. As pointed out by Lang (2002: 272), the literature on note taking and note review by hearing students assumes that students take their own notes. This is a difficult task for most Deaf students in higher education. Language skills and the challenge of attending to multiple visual tasks (interpreters, teacher demonstrations) make note taking unproductive. An investigation into the perceptions of Deaf students regarding the use of hard copy printouts from real-time captioning of classroom lectures reported that such notes can be useful for students in general, not only for deaf students. The researcher strongly agrees as this would serve as a reliable record of information, as nothing that the lecturer says in class would be lost or misinterpreted.

\subsubsection{Real-time captioning}

Real-time captioning is an information technology device where the speaker's message is translated into electronic text as she/he speaks. There are a number of benefits in using real-time captioning, as shared by Stinson, McKee, and Elliot (2000: 62). Firstly, for some real-time captioning systems, the display remains on the screen long enough to allow students to check on and fill in information they might have missed from either the interpreter or the lecturer. Secondly, a hard copy of the complete lecture transcript may be available after class when the captions are stored in a computer's 
memory. Thirdly, exact technical information and specific vocabulary are produced by the captionist. This technique is indeed helpful as Deaf students will be able to concentrate on the lecturer via the interpreter and not worry about missing some of the content. Although it is an expensive system it would be wise for universities to invest in it, as it will help to reduce the barriers to learning for Deaf students.

\subsection{Language rights of the Deaf student}

Before 1994 the rights of deaf people to use SASL were not considered a priority. The majority of deaf and hearing people did not recognise SASL as a language having the same status as spoken languages (Ganiso, 2012:162). Hence the Government's White Paper 6 of 2001 was established to invite higher educational institutions to increase the number of learners with special educational needs that they accept. It requires such institutions to be accountable to government and give plans and time frames for complying. Institutions of higher education are expected to implement the policy of supporting disabled students and, if disputes arise, they should be resolved within the framework of human rights rather than on the basis of entitlement (Matshedisho 2007: 685). For the development of signed language teaching, training and research should be seen as an investment in human rights and equity of access.

Disabled students have no policy or legislative framework for legal recourse in cases of discrimination based on disability. Academic institutions have been providing support services for disabled students at the institutions' discretion and within limited means. The disability rights movements across the world have challenged condescending, discriminatory and stereotypical portrayals of disabled people. Through activism and formulation of the social model of disability, disability can no longer be perceived as a tragic personal state that warrants exclusive medical control, social stigma, welfare, pity and benevolence (Matshedisho 2007: 693). The human rights advantage of inclusive education is that learners would enjoy freedom of choice. For example, they should be able to choose which schools they want to attend, especially those near their homes. In this case, the routine of home and family life are preserved. The other advantage of inclusion is that there is provision of support services for learners who have barriers to learning in a mainstream educational setting. Deaf learners, in particular, may be provided with sign language interpreters, tutors and note-takers (Magongwa, 2008: 46). However, to date, initiatives to accommodate disabled students have failed to specify mechanisms for addressing the execution of their intentions to promote disability support services in higher education. White Paper 6 only mentions that 'It will not be possible to provide relatively expensive equipment and other resources, particularly for blind and deaf students, at all higher education institutions' (Department of Education, 2001: 31).

\subsection{The inclusion of Deaf students in tertiary institutions}

Internationally, the United States of America and Australia have been exemplary in implementing inclusive learning and teaching practices in their educational institutions. The history of inclusive education for all learners is based on efforts to ensure that exclusions based on difference are stopped because they are discriminatory. Findings from international positions on inclusion practices led to countries around the world attempting to develop inclusive educational systems (Magongwa 2008: 40). The debate on inclusive education and international policies indicates that much attention has been devoted to the concept of inclusive education in past years. The notion of inclusion is debated in journals such as the South African Journal of Education, the Journal of the International Academy for Research in Learning Disabilities and the European Journal of Special Needs Education. One of the topics that dominate the debate on inclusion is the issue of educational support services. In South Africa, as stated by the Department of Education (1997), an inclusive education system provides learners with disabilities the opportunity to participate in the educational system of a country. Learners are given an equal right to education and an opportunity to learn. Lastly, the ideal of inclusive education is to remove the stigma attached to learners with barriers to learning and the stereotypical way in which they are viewed.

Napier and Barker (2004: 237) hold that many international changes in education have occurred over recent decades. These changes have had a significant impact on the reform of education in South Africa. It is now evident that the South African education system is gradually being restructured to create a system that can meet the educational needs of all learners. The system is intended to provide an opportunity for all students to learn in an integrated context. Magongwa (2008: 42) claims that in the higher education context, however, the successful implementation of an inclusive education system is both driven and hampered by the availability of resources. These resources are seen as the keys for educational access by students who have faced barriers in an educational setting. It is crucial, therefore, that those students who need support services are provided with them. For educational support services to be accessible to all who need them, core service providers like schools and universities are expected to provide specialist personnel for the unique needs of learners (Magongwa 2008: 43). Also, universities should accommodate their academic programmes, 
related student support services and facilities to the needs of persons with all types of disabilities. This will give Deaf students equal opportunity to gain confidence and skills to help them become valuable members of society.

\section{Conclusion}

In an endeavour to explore ways in which the quality of education for deaf students can be enhanced through access and support services in one institution of higher education, a detailed overview of research in connection with sign language interpreting and information access was given. Thereafter the inclusion of Deaf students in tertiary institutions was briefly discussed. Ideally, Deaf students should always have the option of being educated in a setting where an interpreter is available. Yet, placement in such a setting does not necessarily ensure success for these students. Deaf students bring to the classroom a diverse set of characteristics that influence the way in which members of an education team can assist in their learning and this needs to be embraced. It has also been noted that their lower-than-average level of English literacy is one of the most difficult barriers to learning for Deaf students. Their problem with English is worsened by the poor quality of education in schools for the Deaf, lack of role models at the schools and teachers who are not fluent in SASL. Based on the latter, Ganiso (2012:168) contends that the rights that are enshrined in the Constitution of South Africa also need to be revisited as a point of departure when it comes to the possible official recognition of sign language. Without this official recognition it will be difficult for this language to grow and to receive sanction, which is part of both status and corpus language planning. Therefore, the Deaf community and educational researchers need to challenge and expose the politics of educational practice.

Furthermore, this paper has suggested that the convenience of support services such as SASL interpreters, note taking and real-time captioning in institutions of higher learning is a motivator for Deaf students to access higher education. On another hand, it demonstrates that the cultural and linguistic view of deafness cannot remain unchallenged. While Deaf people share some characteristics with other cultural minority groups, they also share other characteristics with the disability sector (Mogongwa 120). Thus Deaf people are a cultural group with a difference. Their challenge in a social and academic environment is exacerbated because they cannot access spoken languages; a possible solution would be for society to shift from regarding deafness as a welfare issue to a human rights issue. To sum up, the study revealed the challenges and difficulties of Deaf and hard-of-hearing students who are often faced with many challenges in achieving their academic objectives within a university setting. This paper also stressed the need to develop support services for Deaf students.

\section{References}

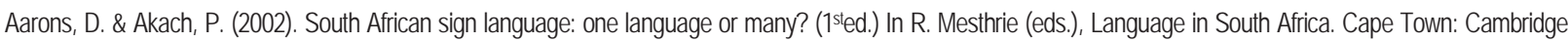
University Press, pp 127-147

Creswell, J.W. (2008). Educational Research: planning, conducting, and evaluating quantitative and qualitative research. (3rded.) New Jersey: Pearson Education, Inc

Donald, D. Lazarus, S. \& Lolwana, P. (1997). Educational Psychology in Social Context: Challenges of Development, Social Issues and Special Needs in South Africa. University of Cape Town: University Press.

Department of Education. (1997). Quality Education For All: Overcoming Barriers to Learning and Development. (National Commission on Special Needs in Education and Training and the National Committee on Education Support Services Report). Parow: CTP Printers.

Department of Education. (2001). Education White Paper 6. Special Needs Education. Building an Inclusive Education and Training System. Pretoria: Government Printers.

Kiyaga, N. \& Tesni, S. (2011). XVI World congress of the world federation of the deaf. Durban, South Africa

Lang, H. G. (2002). Higher education for Deaf students: research priorities on the new millennium. Journal of deaf studies and deaf education, 7 (4), 265-280.

Linchtman, M. (2013). Qualitative research in education: a user's guide. (3rded.) California: SAGE Publications, Inc

Magongwa, L. (2008). Deaf teacher's experience of being students at the University of the Witwatersrand. Unpublished masters' dissertation, Johannesburg: University of the Witwatersrand.

Matshedisho, K. R. (2007). Access to higher education for disabled students in South Africa: a contradictory conjuncture of benevolence, rights and the social model of disability: Disability \& Society, 22 (7), 685-699

McMillan, J. H. \& Schumacher, S. (2006). Research in education: evidence-based inquiry. (6 $6^{\text {thed.) }}$ Pearson Education, Inc

Napier, J. \& Barker, R. (2004). Accessing University Education: perceptions, preferences, and expectations for interpreting by Deaf students: Journal of Deaf Studies and Deaf Education, 9 (2), 228-238

Reagan, T. (2008). South African Sign Language and language-in-education policy in South Africa, Stellenbosch Papers in Linguistics, 38 (2), 165-190

Stinson, M, McKee, B. \& Elliot, L. (2000). Development and implementation of the C-Print speech-to-text support service. In: Albertini, J. Ehrhard, E. \& Strauss, H.C (Eds), Kommunikation und Kreativität. Villingen - Schwennigen, Germany: Neckar-Verlag.

Swift, O. B. (2012). The roles of signed language interpreters in post-secondary education settings in South Africa. Unpublished masters' dissertation, Pretoria: University of the South Africa.

Whyte, A.K. Aubrecht, A.L. McCullough, C.A. Lewis, J.W. \& Thompson-ochoa, D. (2013). Understanding Deaf people in councelling context. [online]. Available at: $\mathrm{http}: / / c t$.councelling.org/2012/10/understanding-deaf-in-councelling-context (October 10, 2013)

World association of sign language interpreters. (2012). "WASLI history of South Africa". [online]. Available at: http://www.wasli.org/wasli-history-p18.aspx (August 8, 2013) 